\title{
Visita domiciliar: percepções de docentes no ensino de enfermagem
}

\author{
Home visit: perceptions of \\ professors in nursing education
}

\author{
Katyane Leite Alves Pereira' 1 (1) \\ Jackeline Kérollen Duarte de Sales ${ }^{2}$ (1) \\ Evanira Rodrigues Maia ${ }^{3}$
}

\section{Rachel de Sá Barreto Luna Callou Cruz ${ }^{4}$ (]) Glauberto da Silva Quirino 5 Antonio Germane Alves Pinto 6 (1)}

'Universidade Brasil (Fernandopólis). São Paulo, Brasil. katyane6@hotmail.com ${ }^{2}$ Autora para correspondência. Universidade Regional do Cariri (Crato). Ceará, Brasil. jackelinekerollen@hotmail.com 3-6Universidade Regional do Cariri (Crato). Ceará, Brasil. evaniramaia@gmail.com, rachel.barreto@urca.br, glaubertoce@hotmail.com, germanepinto@hotmail.com

\begin{abstract}
RESUMO | OBJETIVO: Analisar as percepções de docentes sobre a visita domiciliar no ensino de enfermagem. MÉTODO: Estudo descritivo, com abordagem qualitativa. Realizado na Estratégia de Saúde da Família do município de Picos-PI, local onde ocorreram os estágios curriculares supervisionados do curso de graduação em Enfermagem de uma instituição de ensino superior pública. Para coleta de dados, utilizou-se a entrevista como técnica, e os dados obtidos foram tratados sob a análise de conteúdo de Minayo. RESULTADOS: Emergiram três categorias temáticas que evidenciaram as concepções, processo ensino-aprendizagem e instrumentalização da visita domiciliar nos estágios de enfermagem. CONSIDERAçÕES FINAIS: Os docentes apontam potencialidades do atendimento domiciliar na integralização de habilidades e competências durante a formação de profissionais da saúde. Para a Estratégia de Saúde da Família, constitui-se como método que amplia o cuidado ao sujeito e família, bem como o reconhecimento do território de atuação.
\end{abstract}

DESCRITORES: Visita Domiciliar. Educação em enfermagem. Estratégia Saúde da Família.

\begin{abstract}
OBJECTIVE: To analyze the perceptions of professors about home visits in nursing education. METHOD: Descriptive study with a qualitative approach. Carried out in the Family Health Strategy of the city of Picos-PI, where the supervised curricular internships of the undergraduate Nursing course of a public higher education institution took place. For data collection, the interview was used as a technique and the data obtained were treated under Minayo's content analysis. RESULTS: Three thematic categories emerged that showed the conceptions, teaching-learning process and instrumentalization of home visits in nursing internships. FINAL CONSIDERATIONS: The professors point out the potential of home care in the integration of skills and competences during the training of health professionals. For the Family Health Strategy, it is a method that expands care to the subject and family, as well as the recognition of the territory of action.
\end{abstract}

DESCRIPTORS: Home Visit. Nursing education. Family Health Strategy. 


\section{Introdução}

A atenção à saúde no contexto domiciliar rompe com as formalidades recorrentes do ambiente ambulatorial da assistência e se amplia ao seio familiar com reconhecimento do cotidiano de vida dos usuários. A Estratégia Saúde da Família (ESF) pauta a promoção da saúde e a vigilância do território com práticas interdisciplinares, atuação multiprofissional e ampliação do olhar para a vida comunitária. ${ }^{1}$

No contexto da ESF, a assistência no domicilio caracteriza-se como uma modalidade de atenção essencial para garantir a integralidade e intersubjetividade, inerentes à humanização e ao cuidado, cujo foco está no indivíduo e na família. A Visita Domiciliar (VD) modifica a lógica de oferta e demanda para a integração da atenção e ampliação da satisfação do usuário, em uma cinesia que caminha para o fortalecimento da Atenção Primária à Saúde (APS).?

Desenvolvida pela equipe de saúde da família, a VD viabiliza a valorização das características sociais, políticas, econômicas, culturais e da área de abrangência do território de atuação. Essa intervenção é realizada junto aos usuários, que a percebem como meio de interação efetivo que facilita o cuidado a família. Sendo assim reconhecida como assistência que visa ofertar cuidados no ambiente familiar, que é desinstitucionalizado, complexo e múltiplo em potencialidades. ${ }^{2-4}$

A enfermagem, enquanto categoria profissional que compõe a ESF, precisa atentar-se para a assistência realizada no domicílio e alinhar suas competências e habilidades para essa prática. A comunicação se constitui como elemento essencial para fortalecer o vínculo e a continuidade do cuidado, a fim de alcançar o desenvolvimento de relações terapêuticas horizontais. $\underline{3}$

Assim, por se tratar de uma intervenção relevante, a VD se constitui como elemento que deve permear o ensino de enfermagem, compreendendo que pode alcançar a oferta de um cuidado integral em saúde, atendendo a singularidade de cada usuário que meIhora as condições e qualidade de vida, através da escuta qualificada e do apoio. ${ }^{3}$

O estágio curricular supervisionado (ECS) é o cenário para a aquisição de saberes e práticas na formação de profissionais da saúde. A visão dos preceptores sobre o processo educacional em uma perspecti- va interdisciplinar é importante para construção de ações que respondam às necessidades pedagógicas aplicáveis ao cotidiano. $\frac{5}{}$

A prática da VD realizada pela enfermagem com abordagem integral da população adscrita na ESF, possibilita aos profissionais reconhecer o contexto aos quais os usuários estão inseridos. Potencializa-se pela troca de saberes e práticas voltados à promoção, prevenção e intervenções de saúde no ambiente domiciliar. Nesse sentido, objetivou-se analisar as percepções de docentes sobre a visita domiciliar no ensino de enfermagem.

\section{Método}

Trata-se de um estudo descritivo com abordagem qualitativa realizado na Estratégia de Saúde da Família (ESF) do município de Picos-PI. Nestes territórios, ocorreram os estágios curriculares supervisionados do curso de graduação em Enfermagem de uma Instituição de Ensino Superior (IES) pública.

A coleta de dados foi conduzida no período de março de 2016 a novembro de 2017. Para seleção da população, adotaram-se os seguintes critérios de inclusão: ser docente do curso de graduação em enfermagem, estar ministrando ou ter ministrado disciplinas que possuam estágio curricular na ESF compreendendo a necessidade de contemplar o processo de ensino aprendizagem na formação de enfermeiros para o SUS frente a realização da visita domiciliar. Para exclusão utilizaram-se os critérios: estar de licença saúde ou afastados do exercício da docência.

O quadro do corpo docente do curso de enfermagem da referida IES é composto por vinte e um profissionais; destes, apenas um não possui formação em enfermagem, vinte do sexo feminino e um do sexo masculino, com idades entre 32 a 54 anos, destes, quatorze pertenciam ao quadro permanente e sete ao provisório. Mediante a aplicação dos critérios, foram excluídos 05 que não ministraram disciplinas de estágio, 02 estavam de licença saúde, 02 afastados da docência e 01 recusou participar do estudo. Ao final, a amostra constituiu-se de 11 profissionais.

Para coleta dos dados, utilizou-se a entrevista como técnica, realizada mediante aplicação de roteiro semiestruturado, que ocorreram nas dependências da IES. 
Após ciência e articulação com a Coordenação do Curso de Enfermagem sobre a pesquisa, os docentes foram contactados individualmente e as entrevistas agendadas de acordo com a disponibilidade de cada participante, com duração média de 50 minutos. Foi utilizado um gravador de mp3 para registro das falas, possibilitando a transcrição fiel dos diálogos para posterior análise.

Os dados obtidos foram analisados segundo a perspectiva de Minayo ${ }^{6}$ obedecendo as etapas de pré-análise onde se realizou a leitura flutuante e apreensão do conteúdo também sendo constituídas nesse momento as categorias temáticas. As etapas seguintes de exploração do material e o tratamento dos resultados obtidos seguida da interpretação realizou-se mediante a literatura relevante e pertinente a discussão.

As falas que ilustraram as categorias temáticas tiveram a codificação alfanumérica representada pela ordem de entrevista, por exemplo, para docente 01: código D1.

A participação dos sujeitos ocorreu após o consentimento através da assinatura do Termo de Consentimento Livre e Esclarecido (TCLE). O estudo seguiu os preceitos éticos e legais conforme estimado pela Resolução CNS n466/2012, tem anuência do Comitê de Ética em Pesquisa da Universidade Estadual do Ceará (UECE) sob o parecer 2.096.912 de 2017.

\section{Resultados}

Dos depoimentos dos onze docentes sobre suas experiências, apresentaram-se três categorias temáticas que evidenciaram as percepções, processo ensino-aprendizagem e instrumentalização da VD nos estágios de enfermagem.

\section{Percepção do docente acerca da visita domiciliar}

Entre os docentes, a VD ainda é subentendida como assistência fornecida aos usuários que se encontram impossibilitados de se dirigir ao serviço de saúde. Os atendimentos ocorreram de modo interprofissional realizados de acordo com as necessidades de cada família ou usuário.
D7 - É a assistência à saúde que é prestada no domicilio do paciente, aqueles pacientes que não tem capacidade de se dirigir a unidade de saúde, ou por algum processo patológico ou por alguma deficiência.

D5 - É o atendimento de uma família de forma geral em todas suas características biopsicossociais realizada no próprio domicilio do paciente e da família em si.

D11 - Voltada pra equipe toda da estratégia de saúde da família indo ao encontro da família, na sua residência, dentro também da necessidade, de acordo com as necessidades de cada família ou de cada usuário [...].

Com a realização da VD, é possível identificar fatores determinantes e condicionantes de saúde e conhecer sujeitos que compõem o ambiente familiar.

D2-É um procedimento que permite o conhecimento mais amplo, dos fatores que são determinantes de alguns processos de saúde-doença. É através da visita domiciliar que a gente conhece como aquela família vive[...]

D10- É uma forma de você conhecer ele de uma visão holística, como um todo[...] a partir do momento que você entra dentro da casa dele, a casa já reflete muito da pessoa [...].

A educação na área da enfermagem requer integração entre teoria e prática. Para isso, a VD no processo de ensino e aprendizagem permite a aproximação ao território vivo de interações dos condicionantes e determinantes em saúde.

\section{A prática da visita domiciliar no processo ensino- aprendizagem}

Por ser uma atividade realizada no território, a VD se insere na matriz curricular dos cursos de graduação em enfermagem. Foi no ECS, ofertado no último ano da formação, que os discentes vivenciaram as experiencias da VD na rede de APS.

A VD é identificada como uma experiência concedida aos estudantes no desenvolvimento dos procedimentos que ocorrem na ESF, através da qual se consolidam as diretrizes e princípios doutrinários do SUS. 
D2-O SUS ele precisa de profissionais que se sensibilizem para essa questão do que seriam os próprios princípios ne, integralidade, a equidade da assistência, a universalidade, humanizar [...].

D9-os acadêmicos de enfermagem precisam adquirir conhecimentos, habilidades e atitudes para as funções do enfermeiro [...] aquele estagio requer também a realização de visita domiciliar.

A formação dos profissionais para o SUS com a aplicação da VD possibilita maior apropriação quanto as condições de desigualdade social e melhor competências para reduzir esse contraste.

D2 - [...] o princípio da visita domiciliar é você conhecer as famílias que você tem, quais vivem em condições de maior desigualdade, então isso contribui bastante pra o SUS no sentido que você vai formar um profissional que tenha essa consciência ne, de aumentar cada vez mais a igualdade entre as pessoas.

D10- a visita domiciliar é um momento de interação com o próprio usuário da estratégia e também uma forma de você conhecer ele de uma visão holística, porque as vezes só no consultório você só ver o processo de doença [...], mas você realmente não sabe de fato a realidade, o contexto familiar, social, cultural e de saúde.

A VD abrange todos os ciclos vitais nesse processo de ensino-aprendizagem, para a atenção às crianças, adolescentes, idosos, mulheres e aqueles indivíduos que estão impossibilitados de se dirigirem a unidade de saúde, principalmente os que tem deficiência física ou dificuldade de mobilidade.

D11-A visita é realizada dentro do processo ensino aprendizagem diante da necessidade com relação as disciplinas: saúde do adulto e do idoso, saúde da mulher, saúde da criança e do adolescente [...].

D7- [...]então se faz realmente necessária a visita, principalmente em disciplinas, [...] que se voltam a assistência de saúde coletiva, da saúde pública, no processo de imunização também [...].

Na matriz curricular, existem disciplinas que adotaram a VD como prática para o reconhecimento da realidade familiar.
D5- dentro da grade curricular frente a algumas disciplinas que ministro existe a necessidade de estar conhecendo, de estar visitando o paciente, tentar conhecer a realidade da família, e frente a isso, fazer projetos terapêuticos[...] em saúde mental, para prestar uma assistência melhor ao paciente é importante que se conheça os familiares, o tipo de moradia, as condições que aquele paciente está inserido na família.

A determinação da quantidade de horas/aula também leva em consideração o público que está definido na proposta pedagógica da disciplina, para atribuir a quantidade de VD a serem realizadas. Os docentes reportaram que esta situação depende da disciplina, pois nos estágios são determinadas as atividades, encontros e horas para as VD, com uma média de $30 \%$ da carga horária do estágio.

D3-...vai depender da disciplina ne da carga horária da disciplina então quando a gente está na [..] disciplina saúde da mulher aí a gente tenta dividir nas atividades do posto e tenta ir fazer as visitas isso numa quantidade vamos dizer assim 50\%.

D9- Até o presente momento, os estágios que eu supervisionei do estágio de sessenta horas, é uma média de vinte horas era destinado as visitas domiciliares, no caso doze encontros da disciplina de saúde da mulher, então quatro encontros desses quinze são destinados pra realização da visita puerperal e acompanhamento do $R N$ [...], um estágio de noventa horas que possui dezoito encontros, é uma

media de seis encontros destinado para realização de visita domiciliar daqueles pacientes com diabetes, hipertensão, que já tiveram acidente vascular encefálico ou que possua alguma comorbidade [...] uma média de $30 \%$ da carga horaria do estágio é destinado para visita domiciliar.

Os docentes referiram que o aluno deve aprender como prestar assistência no domicílio, como se apresentar, como se comportar e como conversar com o paciente em seu ambiente familiar além de compreender o real objetivo da visita.

D5- Lá é feito procedimentos também, o profissional adquire habilidades no intuito de conhecer a realidade, de estar confrontando-a, porque as vezes, os problemas do paciente dependem muito de um problema de outro membro da família, de problemas sociais que ali estão envolvidos. 
D3-eu acho que o aluno ele tem que aprender: como

é que ele chega lá no domicilio, até como é que ele conversa no domicilio e a hora dele aprender é agora porque quando ele chegar lá na estratégia "ah vamos fazer uma visita domiciliar", ele não sabe nem como é a chegada, nem como se comportar ao entrar na casa dessa pessoa e como conversar com essa pessoa, então eu acho que é na instituição, no estágio, na formação que é preciso aprender isso... porque na visita a gente vai poder tanto cuidar e orientar, então acho que ela

é importantíssima...A partir do momento em que os discentes aprendem sobre o que é a visita, o que fazer,

quais os objetivos dessa visita, eu acho que vai estar contribuindo sim ne, para o ensino aprendizagem, pra o futuro profissional que eles estão se formando.

D6- é a prática do que a gente ver na teoria em sala de aula, então a prática é tão importante quanto a teoria, uma vez que ela vai dá possibilidade do aluno tá colocando em exercício as suas habilidades ne, as suas competências e realmente o professor lá orientando e avaliando né. A visita, ela é para o aluno conhecer a realidade pra ir preparando-o, pra o mercado de trabalho.

Dessa maneira, enquanto método de aprendizagem necessita de um recurso eficaz para avaliação do desempenho do discente. Na VD, são avaliados a assiduidade e pontualidade do aluno, criatividade, habilidade de comunicação, facilidade em relacionamentos interpessoais, vestimenta, técnica, proatividade, linguagem, empatia, interação, e entre outros.

D5-Existe o instrumento avaliativo geral que avalia a assiduidade, que avalia o aluno no geral, mas não existe um instrumento só pra a visita domiciliar. Os critérios são mais subjetivos, é a parte de o supervisor está analisando como esses alunos conseguem interagir, adquirir dados, realizar os procedimentos que ali são solicitados.

Os docentes apontaram uma avaliação multidisciplinar e integral, que abordava humanização, comunicação, empatia, desenvoltura relacionamento interpessoal e interprofissional. A IES disponibilizou um instrumento padronizado de avaliação que enfoca competências, ética, compromisso, responsabilidade, capacidade técnica, conhecimento prévio a abordagem, o trabalho em equipe, a iniciativa e resolutividade do aluno para as coletas de informações e implementação das orientações e intervenções em saúde, para todas as atividades pedagógicas, sem especificar a VD, exclusivamente.
D2-A gente aborda alguns critérios avaliativos além da assiduidade, da pontualidade, a gente ver também a questão da criatividade, alguns alunos demonstram a capacidade de comunicação melhor, de relacionamento interpessoal melhor, então são alguns critérios adotados.

Na relação docente e discente, vivencia-se a formação de habilidades e competências para fazerem uso dessa aprendizagem em sua atuação profissional.

\section{Instrumentalização e registro da visita domiciliar}

Evidenciou-se que a realização da VD na atenção básica segue desprovida de um roteiro. Os próprios acadêmicos tracejam o planejamento a ser seguido, e muitos dos docentes, optaram por escolher roteiros/ instrumentos preconizados pelo ministério da saúde para realizarem suas atividades acadêmicas.

D11-Bem, sobre o roteiro. Sou eu como profissional, como a orientadora do estágio, eu sempre realizo antes[...]. No meu planejamento esse roteiro é apresentado aos acadêmicos nas aulas práticas pra quando a gente for para os estágios eles estarem aplicando nas visitas domiciliares.

D10- Roteiro, pela instituição de ensino superior, não. o roteiro que eu procuro seguir é o que os manuais do ministério preconizam: o que a gente deve avaliar, o que a gente deve acompanhar dependendo da visita, o motivo da visita que a gente foi, mas pela instituição não.

Sob essa perspectiva, a elaboração de um instrumento próprio e padronizado das visitas domiciliares, contribuiria bastante para o processo de ensinoaprendizagem. O mesmo facilitaria a realização da VD e auxiliaria o aluno na realização da assistência, além de também melhorar o desenvolvimento da prática.

D8- um instrumento específico que orientasse o ensino da visita domiciliar na academia possibilitaria

a melhoria no desenvolvimento da prática e consequentemente a aproximação com a assistência integral, pois você tem que saber e analisar que as vezes a doença ela não é física, ela é social, e isso é percebido e avaliado nesse território.

Os entrevistados informaram que o registro das visitas domiciliares, na maioria das vezes, era feito em locais imprecisos, ou seja, não se tinha um instrumento específico para a realização desse registro. 
D5- O registro é feito no livro de visitas e em fichas de estágios.

D10- A gente faz a evolução de enfermagem com tudo, para poder registrar, passar para o prontuário e discutir...

D11-Com relação ao registro das visitas domiciliares $e$ dos procedimentos que são realizados nela, são feitos nas fichas do E-SUS que a própria unidade de saúde

prioriza.

Este procedimento era feito, a maioria das vezes, em fichas de estágio, folha de evolução, fichas do E-SUS e fichas destinadas a outras atividades. São registradas a evolução de enfermagem, experiências e patologias encontradas.

\section{Discussão}

A VD é assinalada em outras profissões como instrumento de trabalho indispensável ${ }^{7-8}$, para a enfermagem, consiste como método de trabalho cujo escopo é levar ao indivíduo, em seu domicílio, uma assistência e orientação sobre sua saúde. $\stackrel{9}{ }$

O deslocar-se no território para realizar a VD, está apoiado prioritariamente na ideia de acessar pacientes com dificuldade de locomoção, acamados ou com limitações físicas e portadores de doenças crônicas. Na Política Nacional da Atenção Básica (PNAB) o objetivo da VD perpassa a dificuldade ou impossibilidade física de acesso do usuário, e assegura aqueles que necessitam de cuidados ou não, o recebimento da VD impreterivelmente ou quando indicada. $\frac{10}{}$

A valorização da medicamentalização na VD, estabelece relações assimétricas de poder, desconsidera a subjetividade, os saberes e as práticas de cuidado do outro. ${ }^{\beth}$ Mas, cabe aos docentes como formadores a busca da integração dos valores e princípios, segundo as premissas do SUS.

Nessa perspectiva, a VD assume um caráter para o desenvolvimento de estratégias de cuidado no território, momento em que são avaliadas as características de habitação e saneamento e abordadas as noções de risco e agravos à saúde. ${ }^{?}$
Inserir-se nos campos de estágio para as atividades práticas na graduação concede ao discente a aproximação às dimensões do processo de trabalho do enfermeiro. 11 Este momento deve oportunizar práticas pautadas na integralidade onde os profissionais devem ser capazes de compreender o significado do processo saúde-doença e manter relação intersubjetiva no cuidado. Tais atributos compõem as boas práticas do profissional de saúde, qualquer que seja seu local de trabalho. 12

Embora os currículos de formação de profissionais de saúde remetam à discussão de uma abordagem ampliada, a realidade indica o distanciamento das vivências que não confere formação generalista, humanista, crítica e reflexiva. $\frac{13}{\underline{1}}$

A VD viabiliza que aqueles conteúdos vistos na matriz curricular, por vezes tidos como utópicos, ganhem sentido. A realidade que é repleta de conflitos e contradições não é abordada suficientemente nas aulas teóricas ou mesmo nas aulas práticas. Confere-se potencialidade à VD, ponte reflexiva entre a prática pedagógica docente em sala de aula, e a realidade, lugar onde as diversas dimensões desses sujeitos se inter-relacionam e influenciam no desenvolvimento social. $.13-14$

Os docentes estão sensibilizados para práticas em saúde, através de mudanças necessárias para quebra de paradigma emitido pelo modelo biomédico, que se apresenta pela condução do processo ensino-aprendizagem de forma fragmentada e direcionada à doença. Essa fragilidade remete à invisibilidade da família no cenário do cuidado, que deve ser explorado durante a graduação, compreendendo que a vivência preenche possíveis lacunas existentes no ensino. ${ }^{14}$

A obrigatoriedade do Estágio Curricular Supervisionado (ECS) deve ser realizado nos dois últimos semestres do curso, com minimamente $20 \%$ da carga horária total do curso. ${ }^{15}$ Nesse campo, as matrizes curriculares assumem corpo no processo educativo que varia pelas diferentes experiências, valores e interesses trazidos pelos docentes, conferindo a eles a responsabilidade de autoria e execução das propostas curriculares. $\frac{16}{}$

Oportunizar as conduções de práticas no processo de ensino aprendizagem permite que o acadêmico 
experiencie a assistência e compreenda a atuação do enfermeiro nesses processos. Entende-se que há uma complexidade de conhecimentos e temas que permeiam a VD, com flexibilidade e autonomia para adequação às necessidades da família. Assim, possibilita adaptar o currículo à realidade e às necessidades sociais, psicológicas e de saúde.17

Esse período de ECS é significativo na construção das competências e se revela a necessidade de maior ênfase na área da atenção básica, visto que há identificação das fragilidades e realização de diagnósticos gerenciais, em que se viabiliza a proposição de estratégias para a promoção de melhorias no cuidado prestado. ${ }^{15}$ Nessa proposição de currículo para desenvolver uma aprendizagem com integração de diferentes saberes, exige-se o redirecionamento dos modos de ensinar e a reunião de conhecimentos interdisciplinares. $\frac{16}{6}$

Preconizado pelas Diretrizes Curriculares Nacional, o modelo de avaliação baseado nas habilidades e competências necessita do envolvimento dos sujeitos. Como evidenciado nas falas dos docentes, o diálogo permeia a participação do discente durante todos os momentos. Tornar o acadêmico como figura principal do aprendizado transforma a avaliação em solidária, participativa e inclusiva..$^{18}$

Para tanto, não basta mudar conteúdos ou a própria matriz curricular, é preciso mudar as práticas pedagógicas como um todo. É necessária uma coerência entre ensino-aprendizagem-avaliação, não só em relação a conteúdos, mas especialmente a valores que encerram as práticas de saúde e de educação desenvolvidas. $\frac{13}{13}$

Contudo, já se discute as propostas de avaliação por competência, que necessita estar alinhada às mudanças curriculares e às demandas de formação de perfis profissionais em consonância com os princípios do Sistema Único de Saúde. Para isso, a construção de um modelo avaliativo do processo ensino e aprendizagem envolve múltiplas mudanças dentre estas o paradigma, concepções e posturas. $\frac{19}{}$

O uso de instrumento padronizado possibilita avaliação da VD por meio de parâmetros comparáveis..17
Essa dificuldade em uniformizar bem como de priorização das VD, conduz a outros vieses. Dentre estes, a fragmentação da assistência ocasionada pelos intervalos irregulares que por vezes são superiores ao recomendado, principalmente para as famílias que necessitam de um acompanhamento sistemático e intensivo. $\underline{.}$

Em relação à priorização da VD, propõem-se que sejam pautados três aspectos: A dosagem, que irá analisar frequência e tempo de visita; O conteúdo, que observa os objetivos; e o relacionamento, que remete para confiança e engajamento dos sujeitos no processo. ${ }^{17}$ Nisso, verifica-se que o planejamento, condução e análise da VD deve perpassar esses pontos, que são considerados úteis para verificabilidade da eficácia da intervenção.

No entanto, esse modelo centrado na doença condiciona a lógica das práticas à demanda espontânea e reduz a potencialidade de identificação dos profissionais no momento oportuno das situações que exigem cuidados preventivos e diagnóstico precoce, bem como a implementação de ações de promoção da saúde. . $^{-}$

Por fim, evidencia-se a necessidade de inserção de novos instrumentos e modelos que operacionalizem o planejamento, implantação e avaliação de desempenho da visita domiciliar de forma que seja eficiente e atenda aos princípios do SUS.20 Sendo imprescindível à sensibilização dos profissionais para as estratégias, que devem estar focadas na informação e orientação em saúde relacionada à complexidade e à especificidade de cada caso, ou seja, que envolve o encontro intersubjetivo e o relacionamento interpessoal entre dois sujeitos. ${ }^{21}$

\section{Considerações finais}

A percepção dos docentes aponta potencialidades da VD como instrumento que possibilita a integralização de habilidades e competências na formação de profissionais para o SUS. No cotidiano da Estratégia de Saúde da Família, a VD amplia o cuidado ao sujeito e família, bem como, o reconhecimento do território de atuação. Os desafios se apresentaram no sentido de uma sistematização necessária e permanente frente às rotinas dos serviços e usuários. 
As limitações do estudo são expressas pelo olhar uníssono dos docentes que estão implicados com o processo ensino-aprendizagem, pois em estudos futuros, cabe a análise de outras dimensões do cuidado, sujeitos envolvidos e serviços. Indica-se à prática de ensino a aplicação integrada e planejada da atividade no território, com diálogo amplo com as equipes, usuários, docentes e discentes em prol do aprendizado pleno, cuidado integral e resolutividade equânime da atenção domiciliar.

\section{Contribuições dos autores}

Pereira KLA e Pinto AGA participaram da concepção, delineamento, busca e análise estatística dos dados da pesquisa, interpretação dos resultados, redação do artigo científico. Sales JKD, Maia ER, Cruz RSBLC e Quirino GS participaram da análise estatística dos dados da pesquisa, interpretação dos resultados e redação do artigo científico.

\section{Conflito de interesses}

Nenhum conflito financeiro, legal ou político envolvendo terceiros (governo, empresas e fundações privadas, etc.) foi declarado para nenhum aspecto do trabalho submetido (incluindo, mas não se limitando a subvenções e financiamentos, participação em conselho consultivo, desenho de estudo, preparação de manuscrito, análise estatística, etc.).

\section{Referências}

1. Conceição AS, Santana ES, Barbosa MD, Horan M, Santos JB, Paz MJJ, et al. Ações da enfermeira na visita domiciliar da atenção básica. Rev Eletrônica Acervo Saúde. 2019;(20):e441. https://doi. org/10.25248/reas.e441.2019

2. Santos FPA, Acioli S, Machado JC, Souza MS, Rodrigues VP, Couto TA. Práticas de cuidado da equipe da Estratégia Saúde da Família. Rev. enferm. UFPE on line. 2018;12(1):36-43. https://doi. org/10.5205/1981-8963-v12i1a230589p36-43-2018

3. Alves LVV, Acioli S, Correa VAF, Dias JR. Características do acesso à visita domiciliar: visão de enfermeiros. Rev Recien [Internet]. 2020;10(31):57-64. Disponível em: https://recien.com.br/index. php/Recien/article/view/393/pdf_1

4. Assis LMB, Pinheiro ML, Morais MMM, Fernandes DMAP, Melo VFC, Motta MF. Cuidado dentro de casa: reflexões sobre visitas domiciliares na Estratégia Saúde da Família. Saúde Colet. 2021;11(62):5072-81. https://doi.org/10.36489/ saudecoletiva.2021v11i62p5072-5081
5. Lacerda LCA, Teles RBA, Omena CMB. Estágio supervisionado: percepção do preceptor sobre o processo de ensino-aprendizagem em um hospital de ensino. Revista e-Curriculum. 2019;17(2):574-91. https://doi.org/10.23925/18093876.2019v17i2p574-591

6. Minayo MCS. O desafio do conhecimento: pesquisa qualitativa em saúde. 14ª ed. São Paulo: Hucitec; 2014

7. Santana VC, Burlandy L, Mattos RA. A casa como espaço do cuidado: as práticas em saúde de Agentes Comunitários de Saúde em Montes Claros (MG). Saúde Debate. 2019;43(120):159-69. https://doi.org/10.1590/0103-1104201912012

8. Nunes CA, Aquino R, Medina MG, Vilasbôas ALQ, Pinto Júnior EP, Luz LA. Visitas domiciliares no Brasil: características da atividade basilar dos Agentes Comunitários de Saúde. Saúde Debate. 2018;42(2):127-44. https://doi.org/10.1590/0103110420185209

9. Marinho LCR, Ramos FT, Oliveira RC, Caramoni JT, Fontes CMB. Visita domiciliar como suporte da enfermagem na diálise peritoneal: revisão integrativa. Acta Paul Enferm, 2020;33:eAPE20190139. https://doi.org/10.37689/actaape/2020A001395

10. Goulart EP, Moura ATMS, Rafael RMR, Edmundo KMB, Penna LHG. Visita domiciliar pela Estratégia Saúde da Família: limites e possibilidades no contexto da violência urbana no Rio de Janeiro. Rev Bras Med Fam Comunidade. 2021;16(43):2651. https://doi. org/10.5712/rbmfc16(43)2651

11. Jardim SH, Bernardino OS, Ferreira BN, Cacciari P. Contribuições das práticas e estágios no curso de enfermagem para a formação acadêmica. Rev Eletrônica Acervo Saúde. 2021;13(2). https://doi.org/10.25248/reas.e6172.2021

12. Mattos R. Integralidade como Eixo da Formação dos Profissionais de Saúde. Rev bras educ med. 2004;28(2). https:// doi.org/10.1590/1981-5271v28.2-012

13. Maeyama MA, Cutolo LRA, Chaves VM, Barni RS. Projeto Sérgio Arouca: Relato de Experiência. Rev. bras. educ. med. 2018;42(1):47-56. https://doi.org/10.1590/198152712015v40n1e02312014

14. Maestrini E, Martini JG, Lazzari DD, Conceição VM, Geremia DS, Kwiatkowiski HS, et al. Fortalezas e fragilidades no ensino das doenças crônicas não transmissíveis no curso de enfermagem. Cienc Cuid Saude [Internet]. 2020;19:e50409. Disponível em: https://periodicos.uem.br/ojs/index.php/CiencCuidSaude/article/ view/50409/751375150015

15. Rigobello JL, Bernardes A, Moura AA, Zanetti ACB, Spiri WC, Gabriel CS. Estágio Curricular Supervisionado e o desenvolvimento das competências gerenciais: a visão de egressos, graduandos e docentes. Esc Anna Nery. 2018;22(2):e20170298. https://doi.org/10.1590/2177-9465EAN-2017-0298 
16. Franco ECD, Soares AN, Gazzinelli MF. Recontextualização macro e micropolítica do currículo integrado: percursos experimentados em um curso de enfermagem. Esc Anna Nery. 2018;22(4):e20180053. https://doi.org/10.1590/2177-9465EAN-2018-0053

17. Siqueira LD, Reticena KO, Nascimento LH, Abreu FCP, Fracolli LA. Estratégias de avaliação da visita domiciliar: uma revisão de escopo. Acta Paul Enferm. 2019;32(5):584-91. https://doi. org/10.1590/1982-0194201900081

18. Gualdezi LF, Scussiato LA, Peres AM, Rosa TF, Lowen IMV, Torres DG. Avaliação de competências no ensino da enfermagem durante as práticas de campo. Rev Enferm UFSM. 2020;10(e61):118. https://doi.org/10.5902/2179769239939
19. Belem JM, Alves MJH, Quirino GS, Maia ER, Lopes MSV, Machado MFAS. Avaliação da aprendizagem no estágio supervisionado de enfermagem em saúde coletiva. Trab Educ Saúde. 2018;16(3):849-67. https://doi.org/10.1590/1981-7746sol00161

20. Fortes FLS, Lins EM, Varoto AA, Soares LAC, Silva LE, Alves DR. Percepção dos acadêmicos de enfermagem sobre a aplicabilidade teórico-prática das visitas domiciliares: relato de caso. Res., Soc. Dev. 2020;9(12):e40791211333. http://dx.doi.org/10.33448/rsdv9i12.11333

21. Colaço AD, Meirelles BHS, Heidemann ITSB, Villarinho MV. O cuidado à pessoa que vive com hiv/aids na atenção primária à saúde. Texto contexto - enferm. 2019;28:e20170339. https://doi. org/10.1590/1980-265X-TCE-2017-0339 